\title{
Antimycobacterial Activities of Novel 5-(1H-1,2,3-Triazolyl)Methyl Oxazolidinones
}

\author{
Oludotun Adebayo Phillips, ${ }^{1}$ Edet Ekpenyong Udo, ${ }^{2}$ and Reny Varghese ${ }^{1}$ \\ ${ }^{1}$ Department of Pharmaceutical Chemistry, Faculty of Pharmacy, Kuwait University, P.O. Box 24923, Safat 13110, Kuwait \\ ${ }^{2}$ Department of Microbiology, Faculty of Medicine, Kuwait University, P.O. Box 24923, Safat 13110, Kuwait
}

Correspondence should be addressed to Oludotun Adebayo Phillips, dphillips@hsc.edu.kw

Received 17 November 2011; Accepted 14 February 2012

Academic Editor: Zarir Farokh Udwadia

Copyright ( 2012 Oludotun Adebayo Phillips et al. This is an open access article distributed under the Creative Commons Attribution License, which permits unrestricted use, distribution, and reproduction in any medium, provided the original work is properly cited.

\begin{abstract}
The antibacterial activities of a series of triazolyl oxazolidinones against Mycobacterium tuberculosis strain in vitro and in vivo in a mice model are presented. Most active compounds were noncytotoxic against VERO cells with acceptable selectivity indexes (SI) as measures of compound tolerability. Structure activity relationships (SARs) revealed that analogs with alkylcarbonyl (IC ${ }_{90}$ : $<0.2$ to $0.422 \mu \mathrm{g} / \mathrm{mL}$ ) and arylcarbonyl ( $\mathrm{IC}_{90}$ : $<0.2$ to $2.103 \mu \mathrm{g} / \mathrm{mL}$ ) groups at the piperazine $4 \mathrm{~N}$-position-displayed potent antimycobacterium activities, comparable to the methanesulfonyl ( $\mathrm{IC}_{90}:<0.2 \mu \mathrm{g} / \mathrm{mL}$ ) analog, linezolid ( $\mathrm{IC}_{90}:<0.2 \mu \mathrm{g} / \mathrm{mL}$ ), and isoniazid $\left(\mathrm{IC}_{90}:<0.034 \mu \mathrm{g} / \mathrm{mL}\right.$ ). The furanylcarbonyl derivative also displayed potent activity, while the arylsulfonyl analogs were inactive. Of the triazolyl oxazolidinones, the morpholino (PH-27) derivative with medium bioavailability in plasma was most active in vivo, but relatively less efficacious than isoniazid.
\end{abstract}

\section{Introduction}

Tuberculosis (TB) caused by Mycobacterium tuberculosis, a contagious and fatal disease, is considered a global epidemic and a major threat to public health. TB is becoming more prevalent in the world today than any other time in human history. It has been estimated that over a third of the world's population is infected with the TB bacilli, with 9.4 million new cases and nearly 1.7 million deaths in $2009[1,2]$. Most infected people harbor latent TB infection (LTBI), and people with HIV/AIDS and compromised immune system are more likely to develop the disease. TB continues to be a leading cause of death in HIV/AIDS patients, forming a lethal combination.

A number of drugs, namely, isoniazid, rifampicin, ethambutol, and pyrazinamide are often administered over a prolonged period of time and may lead to the development of resistant strains due to patient-poor compliance among other factors. The development and spread of resistant $M$. tuberculosis, pose a vital challenge to the control of TB worldwide. In recent years, the emergence and spread of resistant M. tuberculosis strains has fuelled the TB epidemic by making it more difficult to treat. Multidrug-resistant (MDR) TB, which is resistant to the first line anti-TB agents, namely, isoniazid and rifampicin are increasing with $>500,000 / \mathrm{yr}$ new cases of MDR-TB worldwide [3, 4]. Extensively drugresistant (XDR) TB, resistant to first line anti-TB agents, namely, isoniazid, rifampicin, fluoroquinolones, and one of three injectable drugs, such as capreomycin, kanamycin, or amikacin is awfully difficult to treat and is considered a worldwide threat to TB control [3,4]. These statistics serve as impetus for development of more effective and safer anti-TB drugs [5]. For more than 40 years, there has been a drought of new anti-TB drugs. However, more recently, there are increasing reports of newer agents demonstrating activity against drug-resistant $M$. tuberculosis strains [5-8]. Among these new agents are the oxazolidinones (linezolidLZD; and PNU-100480; Figure 1), diarylquinoline (TMC207; Figure 1), the nitroimidazole-oxazole (OPC-67683; Figure 1), the nitroimidazo-oxazine (PA-824, Figure 1), and some quinolone class of compounds. Linezolid (LZD; Figure 1), a prototypical oxazolidinone used in the clinic to treat gram-positive bacterial infections, the thiomorpholino derivative of LZD (PNU-100480; Figure 1), and others in 


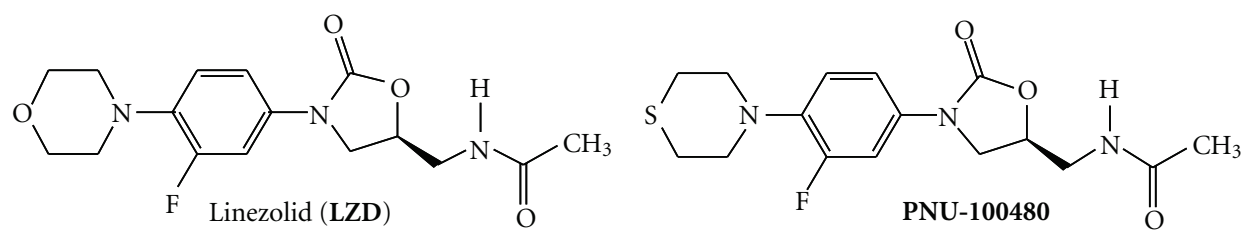<smiles>CCCCOc1ccc(OC2CCN(c3ccc(OC[C@]4(C)Cn5cc([N+](=O)[O-])nc5O4)cc3)CC2)cc1</smiles><smiles>COc1nc2ccc(Br)cc2cc1[C@@H](c1ccccc1)[C@@](O)(CCN(C)C)c1cccc2ccccc12</smiles>

TMC-207

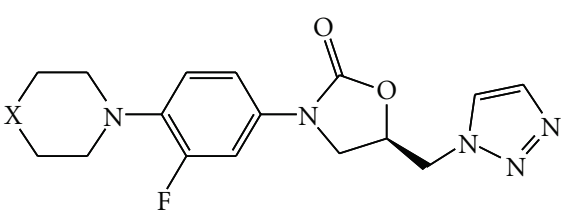

PH-27: $\mathrm{X}=\mathrm{O}$

1a-p: $\mathrm{X}=\mathrm{N}-\mathrm{COR}(\mathrm{R}=\mathrm{H}$, alkyl, cycloalkyl $)$

2a-m: $\mathrm{X}=\mathrm{N}-\mathrm{COR}(\mathrm{R}=$ aryl, heteroaryl $)$

3a-e: $\mathrm{X}=\mathrm{N}-\mathrm{S}(\mathrm{O})_{2} \mathrm{R}^{\prime}\left(\mathrm{R}^{\prime}=\right.$ alkyl, aryl)

FIGURE 1: Chemical structure of oxazolidinone antibacterial agents and novel antimycobacterial agents.

this class, have demonstrated activity against susceptible and drug-resistant $M$. tuberculosis. Our laboratories have been interested in the synthesis of triazolylmethyl oxazolidinones of general structures PH-27, 1, 2, and 3 (Figure 1) with antibacterial activity [9-12]. Studies from other laboratories and ours have shown that the triazolyl oxazolidinones have potent activity against gram-positive bacterial species [9-14], comparable or superior to linezolid in vitro, thus affirming the bioisosteric replacement of the $\mathrm{C} 5$ acetamido functional group by the triazolyl moiety. On the basis of the potent antibacterial activities of the triazolyl oxazolidinones and the demonstrated antimycobacterium activities of representative oxazolidinones, namely, LZD and PNU-100480, we evaluated the antiMycobacterium tuberculosis activity of selected novel triazolylmethyl oxazolidinones synthesized from our laboratories. Therefore, this study outlines the in vitro and in vivo antimycobacterial activity of selected triazolylmethyl oxazolidinones and to establish observable qualitative structure-activity relationships.

\section{Materials and Methods}

2.1. Synthesis of Compounds. The preparation of the compounds 1a-p, 2a-m, and 3a-e has been described previously [9-12]. The reference antituberculosis agents isoniazid (INH) and linezolid (LZD) were provided by the Tuberculosis Antimicrobial Acquisition and Coordinating Facility (TAACF), Southern Research Institute, Birmingham, AL., USA.
2.2. Antituberculosis Susceptibility Testing. The in vitro antitubercular testing was determined according to the protocols of the Tuberculosis Antimicrobial Acquisition and Coordinating Facility (TAACF), USA $[15,16]$. The activity of all compounds against replicating $M$. tuberculosis $\mathrm{H} 37 \mathrm{Rv}$ (ATCC 27294, American Type Culture Collection, Rockville, MD, USA) was performed in BACTEC 12B medium using a fluorescence readout in the Microplate Alamar Blue Assay (MABA) according to the TAACF initial primary screen assays. Compounds were dissolved in $80 \%$ DMSO or $60 \%$ $\mathrm{EtOH}$ in water or $\mathrm{H}_{2} \mathrm{O}$ and tested in ten 2-fold dilutions, ranging from 0.19 to $100 \mu \mathrm{g} / \mathrm{mL}$; the $\mathrm{IC}_{90}(\mu \mathrm{g} / \mathrm{mL})$ values defined as "inhibitory concentration" effecting a reduction in fluorescence of $90 \%$ relative to the controls. The values were determined from dose-response curves, and compounds with $\mathrm{IC}_{90} \leq 10 \mu \mathrm{g} / \mathrm{mL}$ were considered active for antitubercular activity.

2.3. Mammalian VERO Cell Cytotoxicity $\left(C_{50}\right)$ Assay. The compounds were screened to assess toxicity to African green monkey kidney (VERO) cells using the Promage's Cell Titer Glo Luminescent Cell Viability assay by TAACF. The assay returns a $\mathrm{CC}_{50}$ value, which allows a selectivity index (SI: ratio of $\left.\mathrm{CC}_{50} / \mathrm{IC}_{90}\right)$ to be calculated. Compounds with SI value $\geq 10$ are considered safe for further screening.

2.4. Preliminary In Vivo Bioavailability Testing (BioAssay). All in vivo assays/evaluations were determined according to 
TABLE 1: In vitro antimycobacterium activity of 4N-acylpiperazinyl oxazolidinones against $M$. tuberculosis $\mathrm{H} 37 \mathrm{Rv}$.

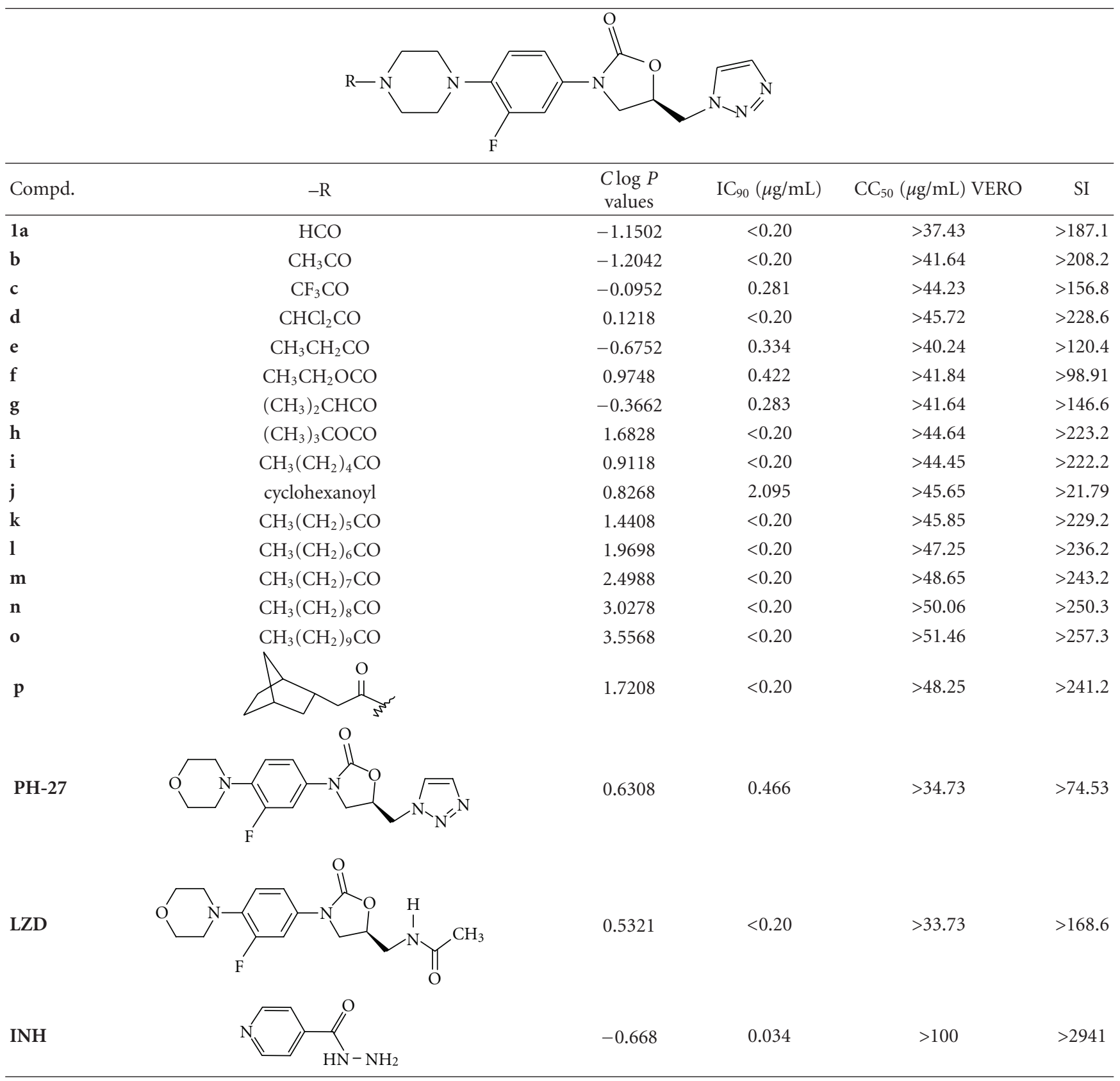

the TAACF protocols [15]. This assay was used to estimate drug levels in mice at specific time points after oral dosing, using the inhibition of growth of $M$. tuberculosis $\mathrm{H} 37 \mathrm{Rv}$ as an indicator for drug activity. Selected compounds were orally dosed $(300 \mathrm{mg} / \mathrm{kg}$ in $0.5 \%$ methyl cellulose) in three C57BL/6 mice and the animals were bled by nicking the lateral vein at $30 \mathrm{mins}$ and $2.5 \mathrm{hrs}$, respectively, to collect blood samples. The blood samples were allowed to clot and centrifuged to collect serum, which were serially diluted and added to 96-well assay plates containing $M$. tuberculosis H37Rv ( $10^{4}$ bacterial) on $100 \mu \mathrm{L} 7 \mathrm{H} 9$ broth with $10 \%$ serum. Each assay also contains lanes of wells with drugs of known concentrations, with or without $10 \%$ mouse serum. Inhibition of bacterial growth was determined by optical density $(\lambda=600 \mathrm{~nm})$ measurements every 3-4 days up to 14 days. The results were further confirmed by visual inspection at 10 days. Inhibition of bacterial growth in the assay ( $<50 \%$ of control without drugs) indicates sufficiently high concentration of compound in blood and hence an acceptable bioavailability.

2.5. In Vivo Efficacy Gamma Knock-Out (GKO) Mouse Model. Interferon gamma knockout female mice C57BL/6 IFN-KO $(n=5)$ unable to control an infection of M. tuberculosis were 
TABLE 2: In vitro antimycobacterium activity of $4 \mathrm{~N}$-arylcarbonyl- and $4 \mathrm{~N}$-arylsulfonyl-piperazinyl oxazolidinones against $M$. tuberculosis H37Rv.

\begin{tabular}{|c|c|c|c|c|c|}
\hline Compd. & $-\mathrm{R}$ & $\begin{array}{c}C \log P \\
\text { values }\end{array}$ & $\mathrm{IC}_{90}(\mu \mathrm{g} / \mathrm{mL})$ & $\mathrm{CC}_{50}(\mu \mathrm{g} / \mathrm{mL})$ VERO & SI \\
\hline $2 a$ & $\mathrm{PhCO}$ & 0.6148 & 0.722 & $>45.04$ & $>62.3$ \\
\hline $\mathbf{b}$ & 4-ClPhCO & 1.4304 & $<0.20$ & $>48.49$ & $>242.4$ \\
\hline c & $3-\mathrm{NO}_{2} \mathrm{PhCO}$ & 0.5198 & 0.759 & $>49.54$ & $>65.27$ \\
\hline d & $2-\mathrm{CH}_{3} \mathrm{PhCO}$ & 1.1138 & 3.375 & $>46.45$ & $>13.76$ \\
\hline e & $3-\mathrm{CH}_{3} \mathrm{PhCO}$ & 1.1138 & 0.422 & $>46.45$ & $>110$ \\
\hline f & $4-\mathrm{CH}_{3} \mathrm{PhCO}$ & 1.1138 & 2.103 & $>46.45$ & $>22.08$ \\
\hline g & $2-\mathrm{CH}_{3} \mathrm{OPhCO}$ & 0.8347 & 1.04 & $>48.05$ & $>46.15$ \\
\hline $\mathbf{h}$ & $3-\mathrm{CH}_{3} \mathrm{OPhCO}$ & 0.8347 & 0.829 & $>48.05$ & $>57.89$ \\
\hline $\mathbf{i}$ & $4-\mathrm{CH}_{3} \mathrm{OPhCO}$ & 0.8347 & 0.843 & $>48.05$ & $>56.93$ \\
\hline $\mathbf{j}$ & 2-furylCO & -0.2092 & $<0.20$ & $>44.04$ & $>220.2$ \\
\hline $\mathbf{k}$ & 2-thienylCO & 0.3913 & 0.209 & $>45.65$ & $>217.3$ \\
\hline 1 & 3-pyridylCO & -0.4862 & 0.236 & $>45.14$ & $>190.4$ \\
\hline m & 2-Cl 3-pyridylCO & 0.2641 & 1.389 & $>48.59$ & $>34.98$ \\
\hline $3 a$ & $\mathrm{CH}_{3} \mathrm{SO}_{2}$ & -0.6042 & $<0.20$ & $>42.44$ & $>212.2$ \\
\hline $\mathbf{b}$ & 2-furylSO ${ }_{2}$ & 1.0658 & $>100(0.419)^{\mathrm{a}}$ & $\mathrm{n} / \mathrm{d}$ & $\mathrm{n} / \mathrm{d}$ \\
\hline c & $\mathrm{PhSO}_{2}$ & 1.3448 & 5.469 & $>48.65$ & $>8.896$ \\
\hline d & $3-\mathrm{CH}_{3} \mathrm{PhSO}_{2}$ & 1.8438 & $>100(1.024)^{\mathrm{a}}$ & $\mathrm{n} / \mathrm{d}$ & $\mathrm{n} / \mathrm{d}$ \\
\hline e & 4- $\mathrm{CH}_{3} \mathrm{PhSO}_{2}$ & 1.8438 & $>100^{\mathrm{a}}$ & $\mathrm{n} / \mathrm{d}$ & $\mathrm{n} / \mathrm{d}$ \\
\hline PH-27 & & 0.6308 & 0.466 & $>34.73$ & $>74.53$ \\
\hline LZD & & 0.5321 & $<0.20$ & $>33.73$ & $>168.6$ \\
\hline INH & & -0.668 & 0.034 & $>100$ & $>2941$ \\
\hline
\end{tabular}

${ }^{a}$ Concentration that inhibited $50 \%$ growth of $M . t b .\left(\mathrm{IC}_{50}\right)$.

infected with M. tuberculosis ATCC 35801 (Erdman strain) by aerosol infection utilizing the Glass-Col Inhalation Exposure System. Treatment was started on day 13 after infection for 9 consecutive daily treatments until day 21. Test compounds were dissolved in $0.5 \%$ methyl cellulose and administered via oral gavage. An isoniazid (INH) control group, administered via oral gavage at $25 \mathrm{mg} / \mathrm{Kg}$ /day $\left(\mathrm{H}_{2} \mathrm{O}\right)$, was included in each study. Mice were sacrificed on day 22 postinfection, and bacterial loads in the lungs and spleen were determined [15]. The Log10 CFU reduction values $>0.30$ generally indicate activity.

\section{Results and Discussion}

The main goals of this study included evaluating the antimycobacterial activities of a series of triazolyl oxazolidinone derivatives 1a-p and $\mathbf{2 a - m}$ and 3a-e, in vitro and in vivo, and explore recognizable structure-activity relationships (SARs) around the phenyloxazolidinone moiety. The synthesis of the compounds was described previously [9-12]. The results from the in vitro and in vivo (mice model) studies, presented in the Tables $1-5$, were determined according to TAACF protocols $[15,16]$. Data from in vitro antimycobacterium 
TABLE 3: In vivo bioavailability of selected oxazolidinones.

\begin{tabular}{|c|c|c|c|c|c|}
\hline Compd. & $\begin{array}{c}\sim \operatorname{MIC}(\mu \mathrm{g} / \mathrm{mL}) \\
-\operatorname{serum}\end{array}$ & $\begin{array}{l}\sim \operatorname{MIC}(\mu \mathrm{g} / \mathrm{mL}) \\
\quad+\text { serum }\end{array}$ & Dilution factor ${ }^{\mathrm{a}}$ & $\sim$ Compd in serum $(\mu \mathrm{g} / \mathrm{mL})$ & Bioavailability $^{\mathrm{b}}$ \\
\hline $1 g$ & 1.1 & 3.3 & $1: 20$ & 22 & low \\
\hline $1 \mathrm{i}$ & 3.3 & 3.3 & 0 & 0 & none \\
\hline 10 & 0.37 & 3.3 & 0 & 0 & none \\
\hline $2 b$ & 3.3 & 3.3 & 0 & 0 & none \\
\hline $2 j$ & 1.1 & 1.1 & 0 & 0 & none \\
\hline $2 \mathrm{k}$ & 1.1 & 1.1 & 0 & 0 & none \\
\hline 21 & 1.1 & 0.37 & $1: 10$ & 11 & low \\
\hline $3 a$ & 0.37 & 1.1 & 0 & 0 & none \\
\hline PH-27 & 1.1 & 0.37 & $1: 80$ & 88 & medium \\
\hline LZD & 0.37 & 0.37 & $1: 320$ & 118.4 & high \\
\hline INH & 0.014 & 0.041 & $1: 320$ & 4.48 & high \\
\hline
\end{tabular}

${ }^{a}$ Dilution factor represents the last dilution step of the serum samples in which drug activity was still observed in the bioassay. (Drug levels in mouse serum are estimated by multiplying the dilution factor by the MIC value of the drug in absence of serum).

${ }^{b}$ Rating of bioavailability: low: activity of drug can be seen in 1 or 2 wells of the bioassay; medium: activity of drug can be seen in 3 or 4 wells of the bioassay; high: activity of drug can be seen in 5 or 6 wells.

TABLE 4: In vivo efficacy and observation at time of sacrifice.

\begin{tabular}{lccc}
\hline Compd. & Lungs & Spleen & Other remarks \\
\hline Control & +++ & 6 enlarged; 1 very large & 2 with enlarged lymph nodes \\
INH & + & 1 slightly enlarged; 4 normal & n/a \\
$\mathbf{2 l}(\mathbf{3 0 6 0 1 9 )}$ & ++ & 1 enlarged; 4 slightly enlarged & Large intestine distended full of feces and air \\
$\mathbf{1 g}(\mathbf{3 0 6 0 2 7})$ & + & 1 slightly enlarged; 4 normal & Large intestine distended full of feces and air \\
PH-27 (306006) & + & normal & Large intestine distended full of feces and air \\
\hline
\end{tabular}

+++ ; highly infected. ++/+; hardly any infected. n/a; not applicable.

and VERO cytoctoxicity assays are presented in Tables 1 and 2. From these data most of the compounds displayed potent to lack of activity against $M$. tuberculosis $\mathrm{H} 37 \mathrm{Rv}$ strain with $\mathrm{IC}_{90}$ values in the range of $<0.2$ to $>100 \mu \mathrm{g} / \mathrm{mL}$, while the reference compounds linezolid (LZD) and isoniazid (INH) showed IC90 values of $<0.2$ and $0.034 \mu \mathrm{g} / \mathrm{mL}$, respectively. The $4 \mathrm{~N}$-acylpiperazinyl derivatives displayed potent activity ( $\mathrm{IC}_{90}$ range of $>0.2-0.422 \mu \mathrm{g} / \mathrm{mL}$, Table 1 ), in comparison to the $4 \mathrm{~N}$-aryl-carbonylpiperazinyl derivatives, which were relatively less active with $\mathrm{IC}_{90}$ in the range of $<0.2-2.103 \mu \mathrm{g} / \mathrm{mL}$. On the other hand, the $4 \mathrm{~N}$ arylsulfonyl derivatives were devoid of antimycobacterium activity ( $\mathrm{IC}_{90}$ range of $5.469-100 \mu \mathrm{g} / \mathrm{mL}$ ), while the methanesulfonylpiperazinyl derivative 3 a showed potent activity with IC $_{90}$ value of $<0.2 \mu \mathrm{g} / \mathrm{mL}$. Although positive correlations between $\log P$ values and antimycobacterium activity have been demonstrated by previous other studies [17], however, such correlations could not be drawn in the present study since the MIC end-points were not determined. The $C \log P$ values of the compounds were estimated using ChemDraw Ultra 8.0.

In this study, interpretation of the in vitro assays $\left(\mathrm{IC}_{90}\right.$ and VERO cell cytotoxicity: $\mathrm{CC}_{50}$ ) data assisted in selection of compounds for further testing in vivo. Hence, data from the selectivity index $\left(\mathrm{SI}\right.$ ratio $=\mathrm{CC}_{50} / \mathrm{IC}_{90}$, Tables 1 and 2$)$ further indicated that most of the active compounds also displayed acceptable safety and therapeutic index profiles, represented by their SI ranges of $>21$ to $>250$. According to the TAACF criteria, compounds with SI value $\geq 10$ are considered safe for further screening. In this regard, nine triazolyl oxazolidinones (1g, 1i, 1o, 2b, 2j, 2k, 2l, 3a, and PH27) along with LZD and INH as reference compounds were selected for preliminary bioavailability study. This bioassay was used to estimate the levels of the drug in mice at specific times after oral dosing. From the results presented in Table 3, the reference compounds LZD and INH displayed high concentrations (118.4 and $4.48 \mu \mathrm{g} / \mathrm{mL}$ ) of the drugs in mice serum, suggesting high bioavailability of the drugs as demonstrated by the activity against $M$. tuberculosis H37Rv in 5 or 6 wells. While three of the triazolyl oxazolidinones, namely, $\mathbf{1 g}$ (4N-isobutyryl), $2 \mathbf{l}$ (4N-nicotinoyl), and PH-27 (morpholino) displayed low to medium concentrations in mice, indicating low-to-medium bioavailability of drugs as demonstrated by activity in only 1 or 2 and 3 or 4 wells of the bioassay, respectively. In addition, the most lipophilic compound, the $4 \mathrm{~N}$-undecanoyl derivative $10(C \log P=$ 3.5568) demonstrated 10 times higher MIC in the presence of serum suggesting that this compound probably has higher protein binding. Although all the other 5 compounds tested also showed relatively insignificant protein binding (Table 3), they also demonstrated no bioavailability similar to that of $4 \mathrm{~N}$-undecanoyl derivative 1o. The probable reason(s) for this 
TABLE 5: In vivo efficacy $\log 10$ CFU reduction in bacterial load in lungs and spleen.

\begin{tabular}{|c|c|c|c|c|c|}
\hline Test group & Organ & $\begin{array}{c}\text { Dose } \\
\mathrm{mg} / \mathrm{Kg} / \mathrm{dy}\end{array}$ & Mean \pm SEM CFU & Log10 CFU reduction & Activity \\
\hline \multirow{2}{*}{ Untreated d13 } & Lung & \multirow{2}{*}{$\mathrm{n} / \mathrm{a}$} & $6.90 \pm 0.11$ & \multirow{2}{*}{$\mathrm{n} / \mathrm{a}$} & \multirow{2}{*}{$\mathrm{n} / \mathrm{a}$} \\
\hline & Spleen & & $4.75 \pm 0.21$ & & \\
\hline \multirow{2}{*}{ Untreated d 22} & Lung & \multirow{2}{*}{$\mathrm{n} / \mathrm{a}$} & $8.06 \pm 0.11$ & \multirow{2}{*}{$\mathrm{n} / \mathrm{a}$} & \multirow{2}{*}{$\mathrm{n} / \mathrm{a}$} \\
\hline & Spleen & & $6.38 \pm 0.07$ & & \\
\hline \multirow{2}{*}{ INH } & Lung & \multirow{2}{*}{25} & $4.77 \pm 0.12$ & 3.29 & Active \\
\hline & Spleen & & $2.04 \pm 0.38$ & 4.34 & Active \\
\hline \multirow{2}{*}{$21(306019)$} & Lung & \multirow{2}{*}{150} & $7.67 \pm 0.22$ & 0.39 & Inactive $^{\mathrm{a}}$ \\
\hline & Spleen & & $6.24 \pm 0.06$ & 0.14 & Inactive $^{\mathrm{a}}$ \\
\hline \multirow{2}{*}{$\lg (306027)$} & Lung & \multirow{2}{*}{300} & $7.28 \pm 0.14$ & 0.78 & Slightly active \\
\hline & Spleen & & $5.95 \pm 0.09$ & 0.43 & Inactive $^{\mathrm{a}}$ \\
\hline \multirow{2}{*}{ PH-27 (306006) } & Lung & \multirow{2}{*}{150} & $6.62 \pm 0.08$ & 1.44 & Active \\
\hline & Spleen & & $4.64 \pm 0.21$ & 1.74 & Active \\
\hline
\end{tabular}

a 306027 : slightly active in lung, but activity in spleen was not statistically significant.

lack of bioavailability of these other 5 compounds could be due to rapid metabolism and/or poor permeability of the compounds.

Finally, the in vivo antimycobacterial activities of the compounds that displayed bioavailability of low to high concentrations were evaluated against gamma knock-out (GKO) C57BL/6 female mice model, which are unable to control aerosol infection with the Erdman strains ATCC 35801. Treatment was initiated 13 days after infection by orally administering the drugs and treatment continued for 9 consecutive days until 21 days. The results of this in vivo study are presented in Tables 4 and 5 following sacrifice of the animals. As can be seen in Table 4, the triazolyl oxazolidinones $1 \mathrm{~g}$ (306027) and PH-27 (306006) demonstrated efficacy comparable to INH in mice lungs and spleen, while 21 (306019) were less efficacious. Generally, the triazolyl compounds were more effective in lungs. Furthermore, mice treated with the triazolyl oxazolidinones presented with distended large intestine. The morpholino derivative $\mathbf{P H}-27$ was the most active of the triazolyl oxazolidinones tested providing $1.44 \log \mathrm{CFU}$ reduction in the lung and $1.74 \mathrm{log}$ reduction in the spleen. While the $4 \mathrm{~N}$-isobutyryl derivative $1 \mathrm{~g}$ showed $0.78 \log$ CFU reduction in the lungs, which was statistically significant, but no statistically significant activity was noted in the spleen. On the contrary, the $4 \mathrm{~N}$-nicotinoyl derivative $\mathbf{2 l}$ did not show statistically significant $\log \mathrm{CFU}$ reduction in either lung or spleen with 0.39 and $0.14 \log$ CFU (Table 5), respectively. However, the reference compound INH provided $3.29 \log$ and $4.34 \log$ CFU reduction in lungs and spleen, respectively.

The main reason for the significant differences in the in vivo efficacy of these three derivatives $4 \mathrm{~N}$-isobutyryl $\mathbf{1 g}$, $4 \mathrm{~N}$-nicotinoyl $\mathbf{2 l}$, and morpholino $\mathbf{P H}-\mathbf{2 7}$ is not clear, apart from the obvious differences in the preliminary bioavailability results. Although the bioavailability studies of the efficacious compounds are very preliminary in nature, the efficacy results seem to go well in hand with the reported oral exposure of the compounds. Previous studies from our laboratory have shown that these class of compounds are relatively stable in plasma at physiologic conditions and may bind to plasma protein [18]. In particular, the most probable reasons for lack of bioavailability of the six triazolyl oxazolidinones $\mathbf{1} \mathbf{i}, \mathbf{1} \mathbf{0}, \mathbf{2} \mathbf{b}, \mathbf{2} \mathbf{j}, \mathbf{2 k}$, and $\mathbf{3 a}$ may be due to rapid in vivo metabolism and/or poor permeability upon oral administration. Further investigations on these class of compounds and other derivatives including their monoamine oxidase inhibitory activities are ongoing in our laboratories.

\section{Conclusion}

This study discloses the in vitro and in vivo antimycobacterium activity of a series of triazolyl oxazolidinones. Most of the compounds displayed potent in vitro activity against $M$. tuberculosis $\mathrm{H} 37 \mathrm{Rv}$, but this in vitro potency was not strongly reflected at the same level in vivo. This could be due to the low bioavailability of the compounds in vivo, however, the precise reason for this is unresolved. In conclusion, these derivatives may serve as templates for further modifications to attain more effective antimycobacterial compounds.

\section{Conflict of Interest}

The authors declare that there is no conflict of or secondary interest.

\section{Acknowledgments}

This work was supported by the Research Administration, Kuwait University Research Grant PC01/05 (OAP), and the Instrument Grants GS01/01, GS01/03, and GS01/05 awarded to the Science Analytical Facilities (SAF). Our gratitude to Tuberculosis Antimicrobial Acquisition and Coordinating Facility (TAACF), USA for performing biological screening assays. 


\section{References}

[1] WHO, "The U.S government and global tuberculosis," Fact Sheet, March 2011.

[2] WHO, "The global tuberculosis epidemic," Fact Sheet, November 2010.

[3] A. Koul, E. Arnoult, N. Lounis, J. Guillemont, and K. Andries, "The challenge of new drug discovery for tuberculosis," Nature, vol. 469, no. 7331, pp. 483-490, 2011.

[4] WHO, "The global tuberculosis epidemic," Fact Sheet, no. 104, November 2010.

[5] A. Matteelli, A. C. C. Carvalho, K. E. Dooley, and A. Kritski, "TMC207: The first compound of a new class of potent antituberculosis drugs," Future Microbiology, vol. 5, no. 6, pp. 849 $858,2010$.

[6] G. F. Schecter, C. Scott, L. True, A. Raftery, J. Flood, and S. Mase, "Linezolid in the treatment of multidrug-resistant tuberculosis," Clinical Infectious Diseases, vol. 50, no. 1, pp. 4955, 2010.

[7] E. C. Rivers and R. L. Mancera, "New anti-tuberculosis drugs in clinical trials with novel mechanisms of action," Drug Discovery Today, vol. 13, no. 23-24, pp. 1090-1098, 2008.

[8] W. W. Yew, M. Cynamon, and Y. Zhang, "Emerging drugs for the treatment of tuberculosis," Expert Opinion on Emerging Drugs, vol. 16, no. 1, pp. 1-21, 2011.

[9] O. A. Phillips, E. E. Udo, A. A. M. Ali, and N. Al-Hassawi, "Synthesis and antibacterial activity of 5-substituted oxazolidinones," Bioorganic and Medicinal Chemistry, vol. 11, no. 1, pp. 35-41, 2003.

[10] O. A. Phillips, E. E. Udo, A. A. M. Ali, and S. M. Samuel, "Synthesis and antibacterial activity of new N-linked 5triazolylmethyl oxazolidinones," Bioorganic and Medicinal Chemistry, vol. 13, no. 12, pp. 4113-4123, 2005.

[11] O. A. Phillips, E. E. Udo, A. A. M. Ali, and S. M. Samuel, "Structure-antibacterial activity of arylcarbonyl- and arylsulfonyl-piperazine 5-triazolylmethyl oxazolidinones," European Journal of Medicinal Chemistry, vol. 42, no. 2, pp. 214-225, 2007.

[12] O. A. Phillips, E. E. Udo, and S. M. Samuel, "Synthesis and structure-antibacterial activity of triazolyl oxazolidinones containing long chain acyl moiety," European Journal of Medicinal Chemistry, vol. 43, no. 5, pp. 1095-1104, 2008.

[13] F. Reck, F. Zhou, M. Girardot et al., "Identification of 4substituted 1,2,3-triazoles as novel oxazolidinone antibacterial agents with reduced activity against monoamine oxidase A," Journal of Medicinal Chemistry, vol. 48, no. 2, pp. 499-506, 2005.

[14] S. I. Hauck, C. Cederberg, A. Doucette et al., "New carbonlinked azole oxazolidinones with improved potency and pharmacokinetics," Bioorganic and Medicinal Chemistry Letters, vol. 17, no. 2, pp. 337-340, 2007.

[15] "Tuberculosis antimicrobial acquisition and coordinating facility (TAACF),” http://www.taacf.org/.

[16] L. A. Collins and S. G. Franzblau, "Microplate Alamar blue assay versus BACTEC 460 system for high- throughput screening of compounds against Mycobacterium tuberculosis and Mycobacterium avium," Antimicrobial Agents and Chemotherapy, vol. 41, no. 5, pp. 1004-1009, 1997.

[17] U. Das, S. Das, B. Bandy, J. P. Stables, and J. R. Dimmock, "N-Aroyl-3,5-bis(benzylidene)-4-piperidones: A novel class of antimycobacterial agents," Bioorganic and Medicinal Chemistry, vol. 16, no. 7, pp. 3602-3607, 2008.
[18] O. A. Phillips, L. H. Sharaf, M. E. Abdel-Hamid, and R. Varghese, "Assessment of the stability of novel antibacterial triazolyl oxazolidinones using a stability-indicating highperformance liquid chromatography method," Medical Principles and Practice, vol. 20, no. 1, pp. 51-59, 2011. 


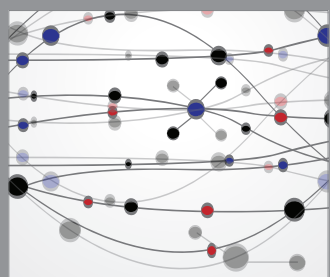

The Scientific World Journal
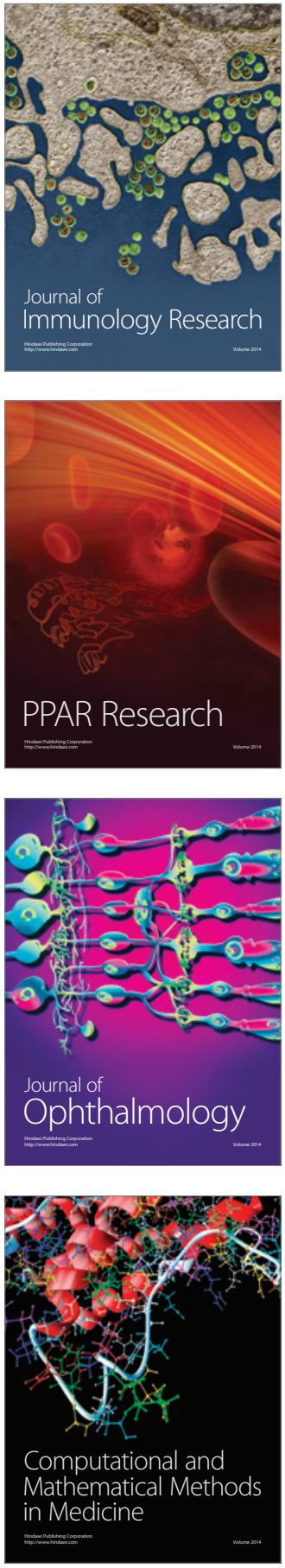

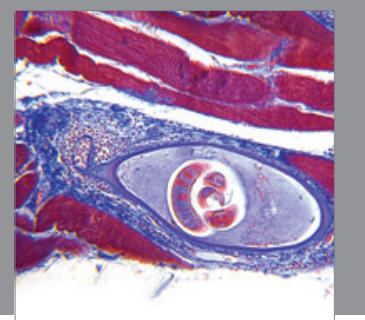

Gastroenterology

Research and Practice
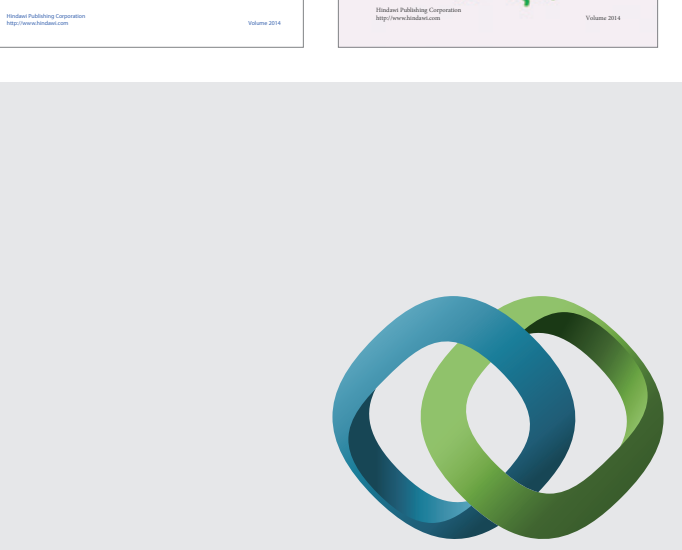

\section{Hindawi}

Submit your manuscripts at

http://www.hindawi.com
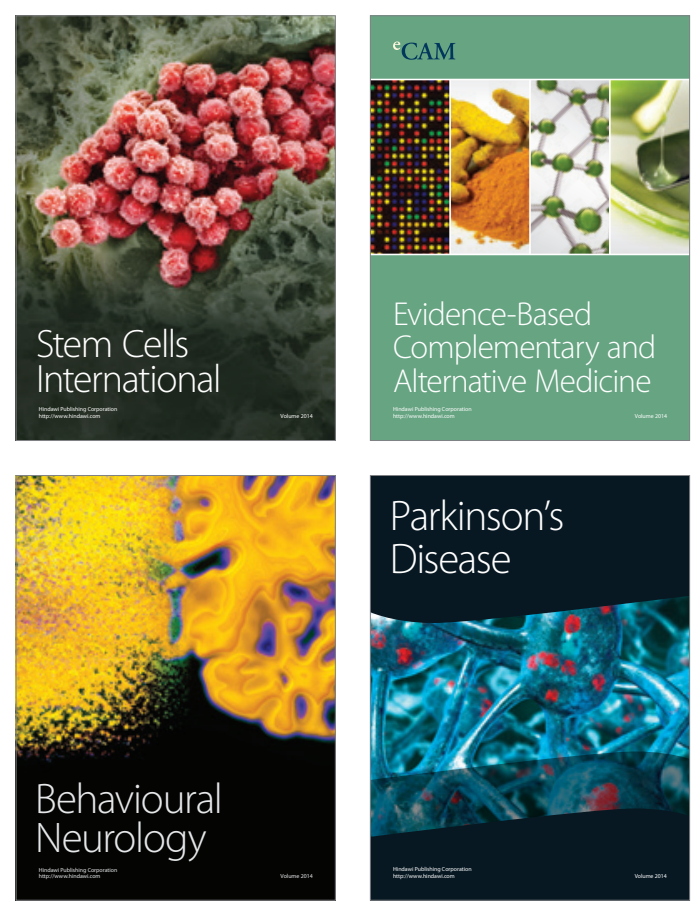

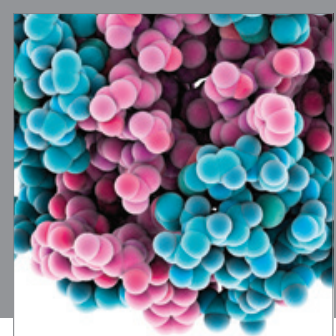

Journal of
Diabetes Research

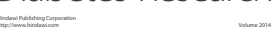

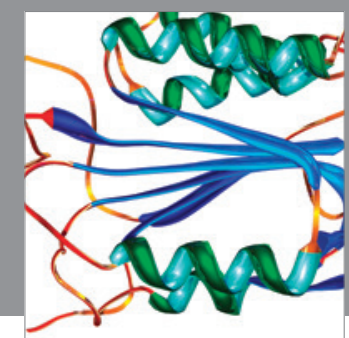

Disease Markers
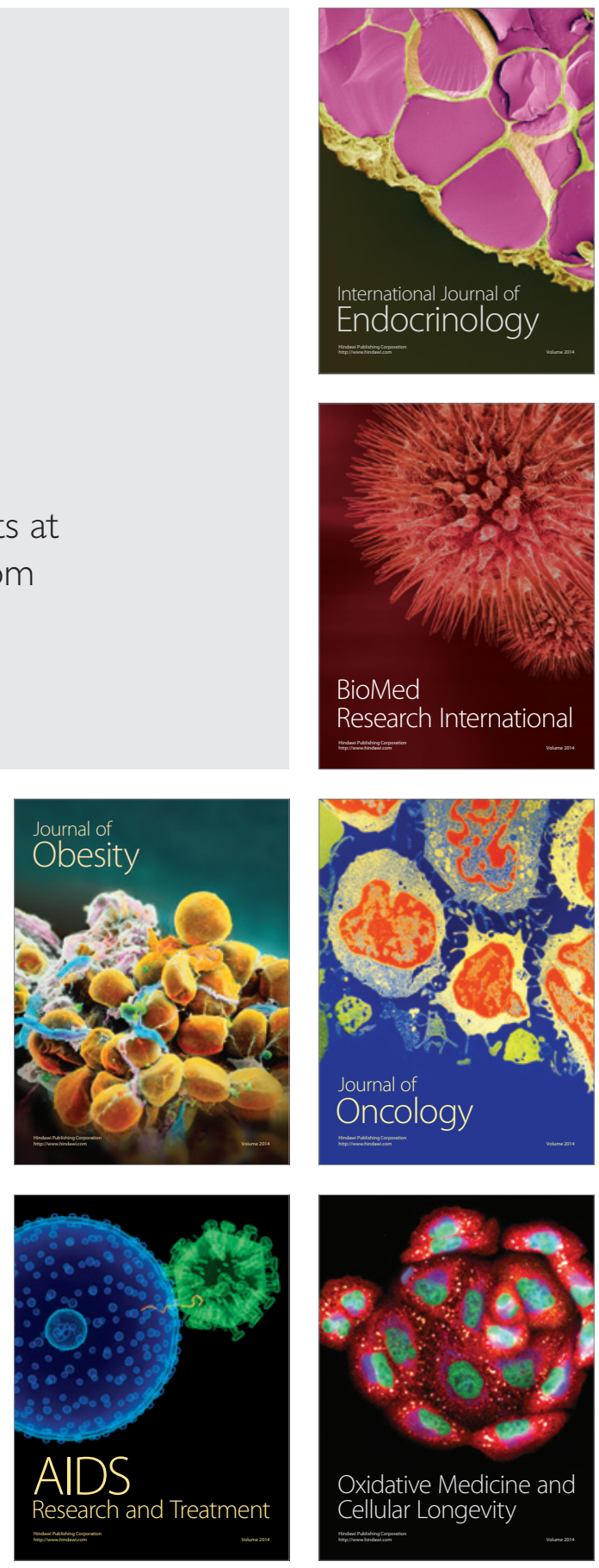